\title{
Extensive islet amyloid formation is induced by development of Type II diabetes mellitus and contributes to its progression: pathogenesis of diabetes in a mouse model
}

\author{
J.W.M. Höppener ${ }^{1}$, C. Oosterwijk ${ }^{1}$, M. G. Nieuwenhuis ${ }^{2}$, G. Posthuma ${ }^{3}$ J.H.H. Thijssen ${ }^{4}$, Th. M. Vroom ${ }^{5}$, \\ B. Ahrén 6 , C.J.M. Lips ${ }^{2}$ \\ ${ }^{1}$ Departments of Internal Medicine and Pathology, University Hospital Utrecht, University of Utrecht, Medical School, Utrecht, \\ The Netherlands \\ ${ }^{2}$ Department of Internal Medicine, University Hospital Utrecht, University of Utrecht, Medical School, Utrecht, The Netherlands \\ ${ }^{3}$ Department of Cell Biology, University Hospital Utrecht, University of Utrecht, Medical School, Utrecht, The Netherlands \\ ${ }^{4}$ Department of Endocrinology, University Hospital Utrecht, University of Utrecht, Medical School, Utrecht, The Netherlands \\ ${ }^{5}$ Department of Pathology, University Hospital Utrecht, University of Utrecht, Medical School, Utrecht, The Netherlands \\ ${ }^{6}$ Department of Medicine, Lund University, Malmö University Hospital, Malmö, Sweden
}

\section{Abstract}

Aims/hypothesis. Type II (non-insulin-dependent) diabetes mellitus is a multifactorial disease in which pancreatic islet amyloid is a characteristic histopathological finding. Islet amyloid fibrils consist of the beta-cell protein "islet amyloid polypeptide" (IAPP)/“amylin". Unlike human IAPP (hIAPP), mouse IAPP cannot form amyloid. In previously generated transgenic mice, high expression of hIAPP as such did not induce islet amyloid formation. To further explore the potential diabetogenic role of amyloidogenic IAPP, we introduced a diabetogenic trait ("ob" mutation) in hIAPP transgenic mice.

Methods. Plasma concentrations of IAPP, insulin and glucose were determined at $3.5(\mathrm{t} 1), 6(\mathrm{t} 2)$, and 16-19 months of age (t3). At $\mathrm{t} 3$, the mice were killed and the pancreas was analysed (immuno)histochemically.

Results. In non-transgenic ob/ob mice, insulin resistance caused a compensatory increase in insulin pro- duction, normalizing the initial hyperglycaemia. In transgenic ob/ob mice, concurrent increase in hIAPP production resulted in extensive islet amyloid formation (more often and more extensive than in transgenic non-ob/ob mice), insulin insufficiency and persistent hyperglycaemia: At $\mathrm{t} 3$, plasma insulin levels in transgenic ob/ob mice with amyloid were fourfold lower than in non-transgenic ob/ob mice $(p<0.05)$, and plasma glucose concentrations in transgenic ob/ ob mice were almost twofold higher $(p<0.05)$. In addition, the degree of islet amyloid formation in ob/ob mice was positively correlated to the glucose:insulin ratio $\left(r_{\mathrm{s}}=0.53, p<0.05\right)$.

Conclusion/interpretation. Islet amyloid is a secondary diabetogenic factor which can be both a consequence of insulin resistance and a cause of insulin insufficiency. [Diabetologia (1999) 42: 427-434]

Keywords IAPP, Amylin, transgenic mice, ob/ob mice, insulin resistance, insulin insufficiency, islet amyloid, diabetogenic factor.
Received: 8 October 1998 and in final revised form: 30 November 1998

Corresponding author: J. W. M. Höppener, University Hospital Utrecht, Department of Pathology, H04.313, P. O. Box 85500, 3508 GA Utrecht, The Netherlands

Abbreviations: IAPP, Islet amyloid polypeptide; hIAPP, human IAPP; NT, non-transgenic; + / +, non-ob/ob; ob, "ob-mutation" in the leptin gene; $\mathrm{PB}$, phosphate buffer; RIA, radioimmunoassay.
Type II (non-insulin-dependent) diabetes mellitus is a common, age-related, multifactorial disease [1,2]. Although still debated, it seems that the primary defect in most subjects developing Type II diabetes involves resistance to insulin action in muscle or liver or in both which initially is compensated for by increased insulin secretion. When in addition insulin production becomes impaired ("beta-cell exhaustion"), however, glucose intolerance or overt diabetes may develop [3-5]. Therefore, factors inhibiting insulin production might promote progression to overt diabetes in subjects with insulin resistance. Islet amy- 
loid formation is such a potential diabetogenic factor at the level of beta-cell function since it has been associated with beta-cell degeneration [6-8]. For the study of multifactorial diseases like Type II diabetes, transgenic mouse technology provides opportunities to investigate the impact of a distinct factor individually. Subsequently, the combined influence of additional factors can be explored, e.g. by crossing with other mouse strains, thus reconstituting multifactorial in vivo models.

Islet amyloid polypeptide (IAPP)/amylin, is a 37 amino acid beta-cell protein $[9,10]$. Since mouse IAPP is not amyloidogenic [11], all non-transgenic mouse models for Type II diabetes lack the potential for islet amyloid formation and consequently the opportunity to assess its impact. Transgenic mice overproducing human IAPP (hIAPP) have been generated previously to study the potential diabetogenic role of amyloidogenic IAPP [12]. In this transgenic mouse model, high expression of hIAPP as such apparently was not sufficient to induce islet amyloid formation. Therefore, in this study we have crossed hIAPP transgenic mice with "ob" mice, which in homozygous animals (ob/ob) develop insulin resistance and diabetes due to a mutation in the leptin gene [13]. This enabled us to explore whether the combination of a diabetogenic trait together with hIAPP production would cause islet amyloid formation, thus also providing an opportunity to study the effect of islet amyloid formation on the development of diabetes. Data on plasma concentrations of IAPP, insulin and glucose, obtained from individual mice at different ages, provided information on the longitudinal development of insulin resistance, beta-cell failure and eventual insulin insufficiency. In addition, assessment of the degree of islet amyloid formation in hIAPP ob/ ob mice enabled correlations to be drawn with the metabolic variables at these different ages, providing further insight into the role of amyloidogenic IAPP in the development of Type II diabetes mellitus.

\section{Materials and methods}

Animals. Transgenic mice overproducing human IAPP (hIAPP) under transcriptional control of a rat insulin 2 gene promoter, had been generated previously [12]. Transgenic lines were maintained by breeding heterozygous hIAPP mice with $\mathrm{C} 57 \mathrm{Bl} / 6 \mathrm{~J}$ mates. C57Bl/6J-ob/Ola/Hsd $(\mathrm{ob} /+)$ mice (Harlan UK Limited, Oxon, England) were mated with hIAPP heterozygotes of lines No14 and No18, which were selected to evaluate the effect of different expression levels of the hIAPP transgene. $\mathrm{Ob} /$ + mice of the F1 generation were selected using Southern dot-blots of PCR products, generated on tail DNA using leptin gene oligonucleotides. Dot-blots were hybridized with oligonucleotides corresponding to the "ob" point-mutation [13] or to the corresponding wildtype sequence. Human IAPP ob/ob mice and non-transgenic ob/ob mice were generated by matings between ob/ + mice of the F1 generation (only homozygous ob/ ob mice develop the obese phenotype). Heterozygosity or ho- mozygosity for the hIAPP transgene was assessed by quantification of the hybridization signal of tail DNA using a hIAPP specific probe for Southern dot-blot analysis.

Mice were housed on hardwood bedding in polypropylene cages and maintained in air-conditioned rooms at $20-22^{\circ} \mathrm{C}$ with a photoperiod of $12 \mathrm{~h}$ light, $12 \mathrm{~h}$ dark. Water was available continuously and commercial mouse diet (RMH-TM, Hope Farms, Woerden, The Netherlands) was provided ad libitum. This diet contained $4,500 \mathrm{kcal} / \mathrm{kg}$ and included $22.5 \%$ protein and $4.8 \%$ fat. The body weight was determined at 4 -week intervals and the maximum body weight was used for comparison between the different groups of mice.

Protocols for the animal experiments were approved by the Committee for Animal Experimentation of the Medical Faculty of Utrecht University.

Plasma measurements. Blood from the retro-orbital plexus was obtained from mice both at 3.5 months (t1) and at 6 months (t2) of age after an overnight fast and again from the same mice without fasting at the time of killing ( $\mathrm{t} 3$ ) (on average 16-19 months of age for the different groups of mice). For some transgenic as well as some non-transgenic non-ob/ob $(+/+)$ mice, blood was available only from $t 3$, increasing the power of statistical analyses at this point in time. Blood was collected in EDTA-tubes, which were kept on ice until centrifugation at $1500 \mathrm{~g}$ for $5 \mathrm{~min}$ at $4{ }^{\circ} \mathrm{C}$. Plasma was taken, divided in aliquots and stored at $-80^{\circ} \mathrm{C}$ until analysis. Immunoreactive IAPP was measured in 50-100 $\mu$ l plasma by radioimmunoassay (RIA) as described [12, 14], using hIAPP antiserum K1338 that shows full cross-reactivity with synthetic rat IAPP(1-37), which is identical to mouse IAPP(1-37). Thus, the sum of endogenous mouse IAPP plus transgenic hIAPP was determined. Immunoreactive insulin was measured in $20 \mu \mathrm{l}$ plasma using a RIA with the use of a guinea pig anti-rat insulin antibody, ${ }^{125}$ I-human insulin as tracer and rat insulin as standard (Linco Research, St. Charles, Mo, USA). Free and bound radioactivity was separated by use of an anti-IgG (goat anti-guinea pig) antibody (Linco). The sensitivity of the assay is 12 $\mathrm{pmol} / \mathrm{l}$ and the coefficiency of variation is less than $3 \%$. Cross-reactivity with proinsulin is less than $0.2 \%$. Glucose concentrations were determined in $10 \mu$ l plasma using the glucose oxidase method.

Histological analysis. Specimens of the pancreas from nonfasted mice were fixed in $4 \%$ phosphate-buffered formalin (pH 7.4) for 24 to $48 \mathrm{~h}$ and paraffin embedded. Immunohistochemical staining on paraffin sections was done using polyclonal primary antisera, biotinylated second antibodies (1:500 final dilution) (Vector, Burlington, USA) and horseradishperoxidase-streptavidine conjugate (Boehringer Mannheim, Mannheim, Germany). The human-specific antiserum ASK1353 (1:1000) was raised against a flanking peptide of hIAPP (amino acids 74 to 89 of the 89 amino acids hIAPP precursor) and has been described previously [12]. The insulin antiserum (1:500) was raised against porcine insulin (DAKO, Glostrup, Denmark).

Congo red staining of pancreas sections, adjacent to those used for immunohistochemistry, was done for detection of amyloid deposits. Congo red stained sections were examined by polarized light microscopy, which shows an "apple-green" birefringence of amyloid deposits, and by ultraviolet light microscopy which makes autofluorescent Congo red stained material visible. To quantify the degree of islet amyloidosis in each mouse, we defined an "Amyloid Index" based on a semiquantitative assessment: the per cent of individual islet areas occupied by Congo red positive deposits was estimated as $0 \%$ (score 0 ), between 0 and $26 \%$ (score 1 ), 26-50\% (score 2), 
51-75\% (score 3) or 76-100\% (score 4). The Amyloid Index (range $0-100)$ was calculated as $(1 \times \mathrm{N} 1+2 \times \mathrm{N} 2+3 \times \mathrm{N} 3+$ $4 \times \mathrm{N} 4) \times 25 / \mathrm{n}$, where $\mathrm{N} 1$ is the number of islets with score 1 , etc. and $n$ is the total number of islets investigated (on average 16 for the non-ob/ob $[+/+]$ mice and 35 for the ob/ob mice). The degree of islet amyloid formation was determined with the investigator being unaware of the genetic status of the animals (i.e. "blind").

Electron microscopy. Islets of Langerhans were isolated from specimens of the pancreas from non-fasted mice. Pancreatic tissue was cut into small $\left(2 \mathrm{~mm}^{3}\right)$ pieces, placed in a glass dish containing a solution of $2.5 \mathrm{mg} / \mathrm{ml}$ collagenase (Sigma, Poole, UK) in modified Hanks medium (137 mmol/l NaCl, $1.2 \mathrm{mmol} /$ $1 \mathrm{NaH}_{2} \mathrm{PO}_{4}, 4.2 \mathrm{mmol} / \mathrm{l} \mathrm{NaHCO}{ }_{3}, 5.6 \mathrm{mmol} / \mathrm{l} \mathrm{KCl}, 1.2 \mathrm{mmol} / \mathrm{l}$ $\mathrm{MgCl}_{2}, 2.6 \mathrm{mmol} / 1 \mathrm{CaCl}_{2}, 10 \mathrm{mmol} / \mathrm{l} \mathrm{HEPES}, 5.6 \mathrm{mmol} / \mathrm{l} \mathrm{glu}-$ cose, $\mathrm{pH} 7.4$ ), and shaken at $37^{\circ} \mathrm{C}$ until a homogeneous digest was obtained. The digest was then washed three to four times in modified Hanks medium and fixed in $2.0 \%$ paraformaldehyde $/ 0.2 \%$ glutaraldehyde in $0.1 \mathrm{~mol} / \mathrm{l}$ phosphate buffer, $\mathrm{pH}$ 7.2 (PB). After $2 \mathrm{~h}$ the fixative was removed and the specimens were stored in $2.0 \%$ paraformaldehyde in PB. After $18 \mathrm{~h}$ the specimens were washed three times with $\mathrm{PBS} / 0.15 \mathrm{~mol} / \mathrm{l}$ glycine and finally embedded in $10 \%$ gelatin in PB. The gelatin was allowed to solidify, and small cubic blocks were cut at $4^{\circ} \mathrm{C}$ and infused with $2.3 \mathrm{~mol} / 1$ sucrose in PB during at least $2 \mathrm{~h}$ at $4^{\circ} \mathrm{C}$. The blocks were mounted on a copper specimen holder and frozen in liquid nitrogen. Ultrathin cryosections were prepared at $-120^{\circ} \mathrm{C}$ on a Leica Ultracut S (Vienna, Austria) using a Drukker diamond knife (Drukker International, Cuick, The Netherlands) as described [15]. The sections were immuno-labelled with an antiserum against rat IAPP1-37 (Peninsula, Belmont, Calif., USA, 1:100) and protein A-gold $10 \mathrm{~nm}$ (Department of Cell Biology, Utrecht University, The Netherlands) according to Slot et al. [16]. This procedure showed immunoreactivity on beta-cell granules of mice (mouse IAPP is $100 \%$ identical to rat IAPP [11]) and humans (human IAPP is $83 \%$ identical to rat IAPP [11]). Contrast was enhanced with uranyl acetate and lead citrate.

Statistics. Results were calculated as means \pm SEM. Statistical difference between groups was calculated using the non-parametric Mann-Whitney U test. The relations between Amyloid Index and plasma concentrations of IAPP, insulin and glucose, as well as the glucose:insulin ratio in ob/ob mice, were analysed using the non-parametric Spearman's rank correlation $\left(r_{\mathrm{s}}\right) . P$ values indicate the probability level of random difference between groups or of random correlation, respectively. $P$-values less than 0.05 were considered to represent statistical significance.

\section{Results}

Plasma concentrations of IAPP, insulin and glucose. Figure 1 presents data on fasted plasma concentrations of IAPP, insulin, and glucose from mice at an average age of 3.5 months (t1) and 6 months (t2), as well as non-fasted plasma concentrations at the age of killing (t3): $19.2 \pm 0.4$ months for non-ob/ob $(+/+)$ mice and $16.7 \pm 0.6$ months for ob/ob mice. The maximum body weight was $38.1 \pm 0.8 \mathrm{~g}$ for $+/+$ mice and $82.0 \pm 1.9 \mathrm{~g}$ for $\mathrm{ob} / \mathrm{ob}$ mice. Human IAPP $+/+$ mice had two to fivefold higher plasma IAPP concentra-
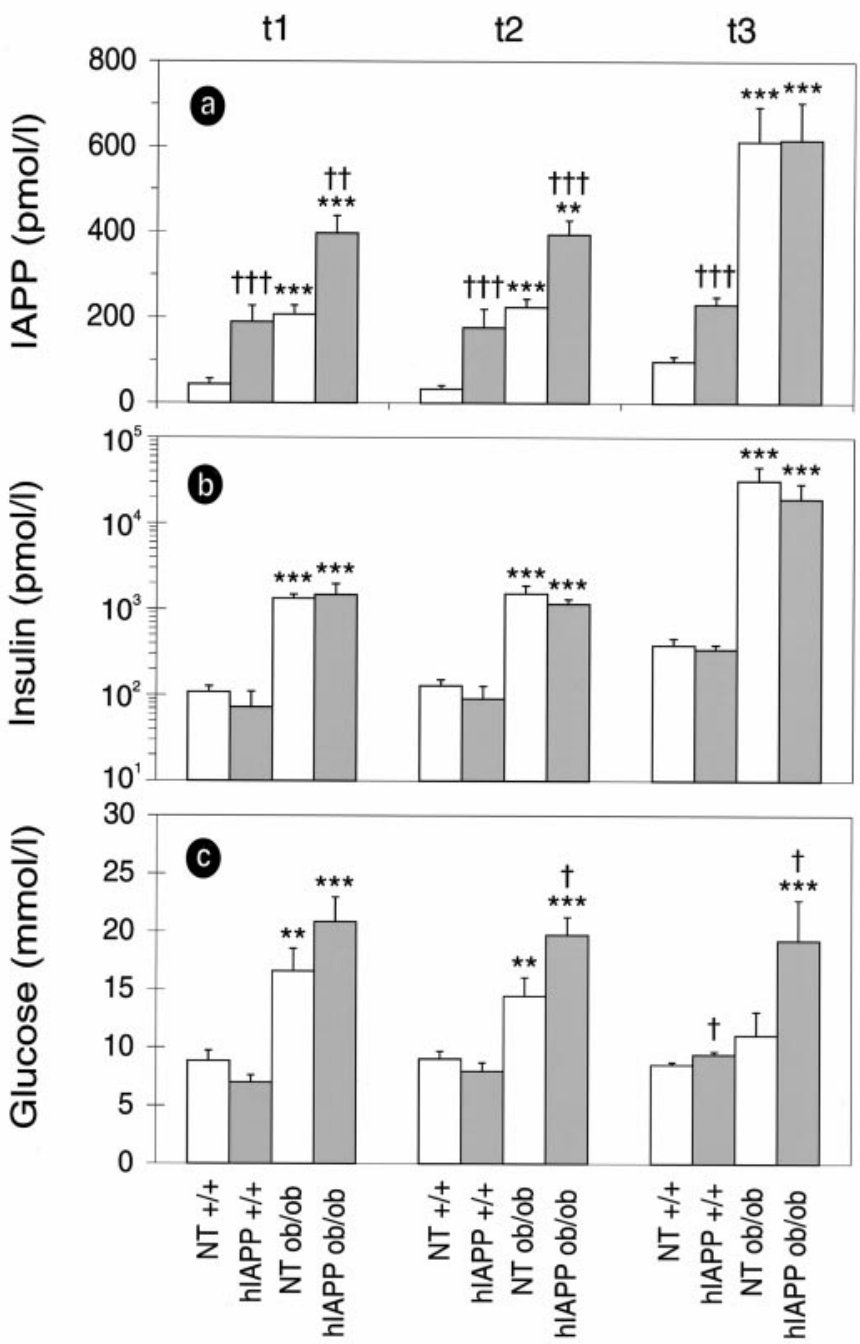

Fig. 1a-c. Fasted plasma concentrations of (a) IAPP, (b) insulin (logarithmic scale) and (c) glucose were determined at 3.5 months of age (t1) and at 6 months of age (t2). Non-fasted plasma concentrations were determined at the time of killing (on average 16-19 months of age, $\mathrm{t} 3$ ), when the pancreas was removed for (immuno)histochemical analyses. For t1 and t2, $n=13,11,9$, and 11, for the non-transgenic non-ob/ob (NT +1 + ), human IAPP transgenic non-ob/ob (hIAPP +/+), NT ob/ ob and hIAPP ob/ob mice, respectively. For $\mathrm{t} 3, n=21,33,8$ and 10 , for these groups of mice, respectively (from both ob/ ob groups, one mouse had died before a blood sample for $\mathrm{t} 3$ could be taken). Figures are means, the SEM is indicated by vertical bars. Statistically significant differences between hIAPP and corresponding NT mice ( $\dagger$ ), as well as between ob/ob and corresponding $+/+$ mice $(*)$ at each of the three ages, are indicated. $p$-values for these comparisons are $<0.05(*, t)$, $<0.01(* *,+\dagger)$, or $<0.001(* * *,+\dagger+)$, respectively

tions than their non-transgenic (NT) $+/+$ littermates (Fig. 1 a). In all ob/ob mice plasma IAPP concentrations were greatly increased. At the younger ages plasma IAPP concentrations were twofold higher in the hIAPP ob/ob mice than in the NT ob/ob mice ( $p=0.002$ at $\mathrm{t} 1$ and $p=0.001$ at $\mathrm{t} 2$ ) but at $\mathrm{t} 3$ the average IAPP concentration in these two groups of mice did not differ significantly. 


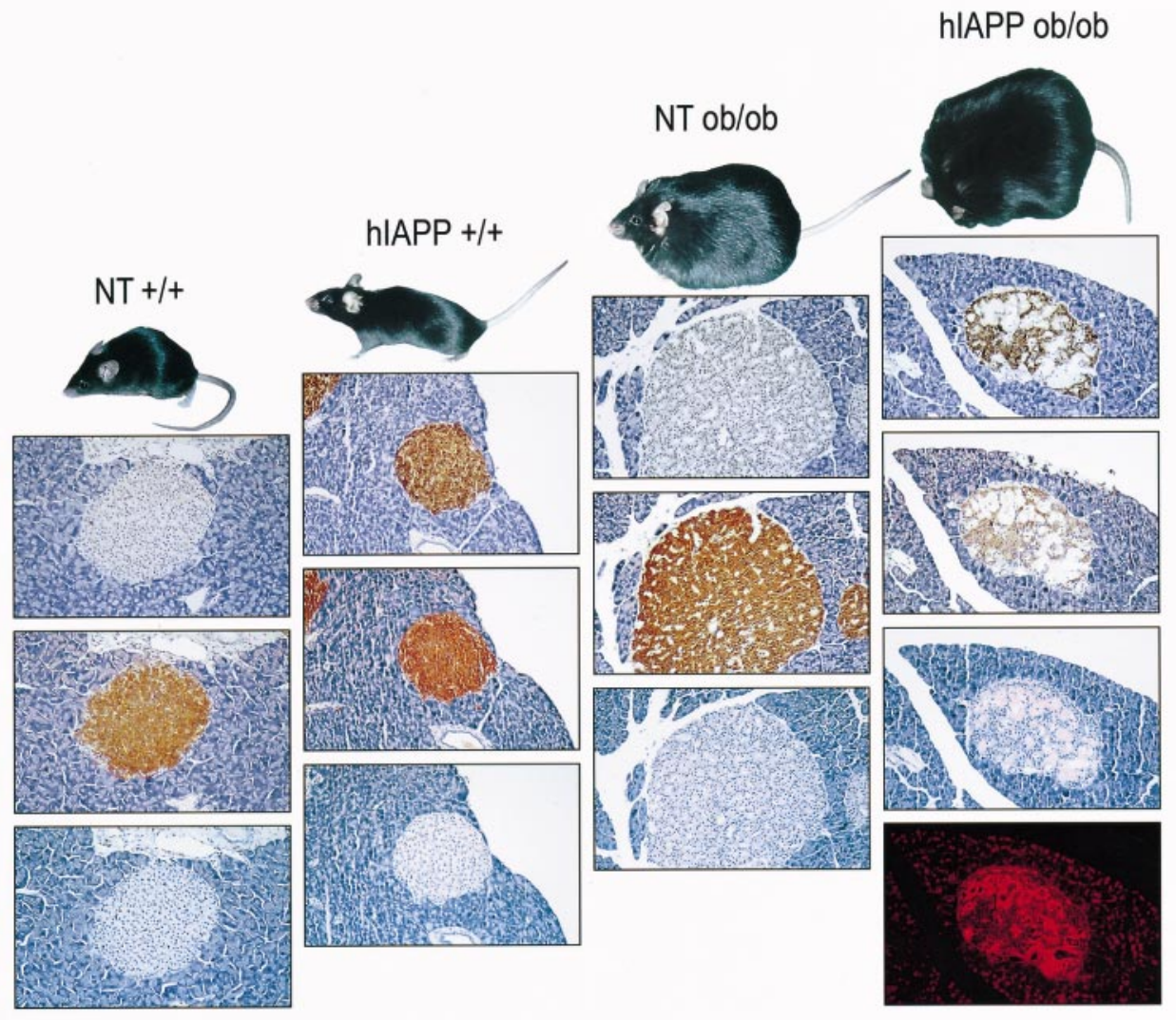

Fig. 2. (Immuno)histochemistry of the pancreas of a male wildtype mouse (NT $+/+, 24$ months old), a male heterozygous transgenic hIAPP mouse (hIAPP $+/+, 17$ months old), a male non-transgenic ob/ob mouse (NT ob/ob, 17 months old) and a male heterozygous transgenic hIAPP ob/ob mouse (hIAPP ob/ob, 17 months old). Paraffin sections were incubated with a human-specific antiserum to a flanking peptide of IAPP (top panel), or with an insulin antiserum (second panel from the top). Congo red staining (third panel from the top) showed extensive pink-coloured amyloid deposits in islets of Langerhans of hIAPP ob/ob mice. Amyloid deposits were made most prominently visible with UV light microscopy (bottom panel for the hIAPP ob/ob mouse, same islet as top panels). Original magnification is $\times 50$

Table 1. Genotype- and gender-specificity of islet amyloid formation (IA) as detected by Congo red staining of pancreas sections at 16-19 months of age (t3) in non-transgenic (NT) and human IAPP transgenic (hlAPP) non-ob/ob $(+/+)$ and ob/ob mice

\begin{tabular}{lllll}
\hline & $\begin{array}{l}\text { NT } \\
+/+\end{array}$ & $\begin{array}{l}\text { hlAPP } \\
+/+\end{array}$ & $\begin{array}{l}\text { NT } \\
\text { ob/ob }\end{array}$ & $\begin{array}{l}\text { hlAPP } \\
\text { ob/ob }\end{array}$ \\
\hline IA-positive males & $0 / 10$ & $4 / 14$ & $0 / 3$ & $5 / 6$ \\
IA-positive females & $0 / 11$ & $2 / 19$ & $0 / 6$ & $1 / 5$ \\
Total number of mice & $0 / 21$ & $6 / 33$ & $0 / 9$ & $6 / 11$ \\
\hline
\end{tabular}

Also the plasma insulin concentrations were greatly increased in all ob/ob mice (Fig. 1b). Pancreatic islets of ob/ob mice showed beta-cell hyperplasia, enabling these mice to produce large amounts of insulin in order to compensate for the severe insulin resis-

tance caused by the homozygous leptin gene mutation.

In hIAPP + / + mice plasma glucose concentrations were slightly higher than in $\mathrm{NT}+/+$ mice only at $\mathrm{t} 3(p=0.02)$ (Fig. 1c). In the NT ob/ob mice, the hyperglycaemia at 3.5 and 6 months of age had practically returned to normal at 18 months of age. In hIA$\mathrm{PP}$ ob/ob mice, plasma glucose concentrations were higher than in NT ob/ob mice at $\mathrm{t} 2$ and $\mathrm{t} 3$, and their hyperglycaemia was persistent. In the hIAPP ob/ob mice, plasma insulin concentrations were not increased compared with NT ob/ob mice, despite these increased plasma glucose concentrations. On the contrary, plasma insulin concentrations tended to be lower at $\mathrm{t} 2$, and particularly at $\mathrm{t} 3(p=0.10)$ (Fig. 1b) and, consequently, the glucose:insulin ratios were considerably higher in hIAPP ob/ob mice at $\mathrm{t} 3(15.8 \pm 8.4 \times$ $\left.10^{6}, n=10\right)$ than in NT ob/ob mice $\left(0.8 \pm 0.2 \times 10^{6}\right.$, $n=8)(p=0.04)$. Hence, the introduction of hIAPP expression aggravated hyperglycaemia in ob/ob mice and induced a failure of an adequate insulin response to these increased plasma glucose concentrations.

Islet amyloid formation. In non-transgenic mice, either lean or obese, euglycaemic, hyperglycaemic or diabetic, islet amyloid deposits were not observed (Table 1). In hIAPP + / + mice, only a few, small amyloid deposits were detected in $5-25 \%$ of the islets in 6/33 animals. In 6/11 hIAPP ob/ob mice extensive islet amyloid formation was observed, particularly in males. In these mice, amyloid was present in 


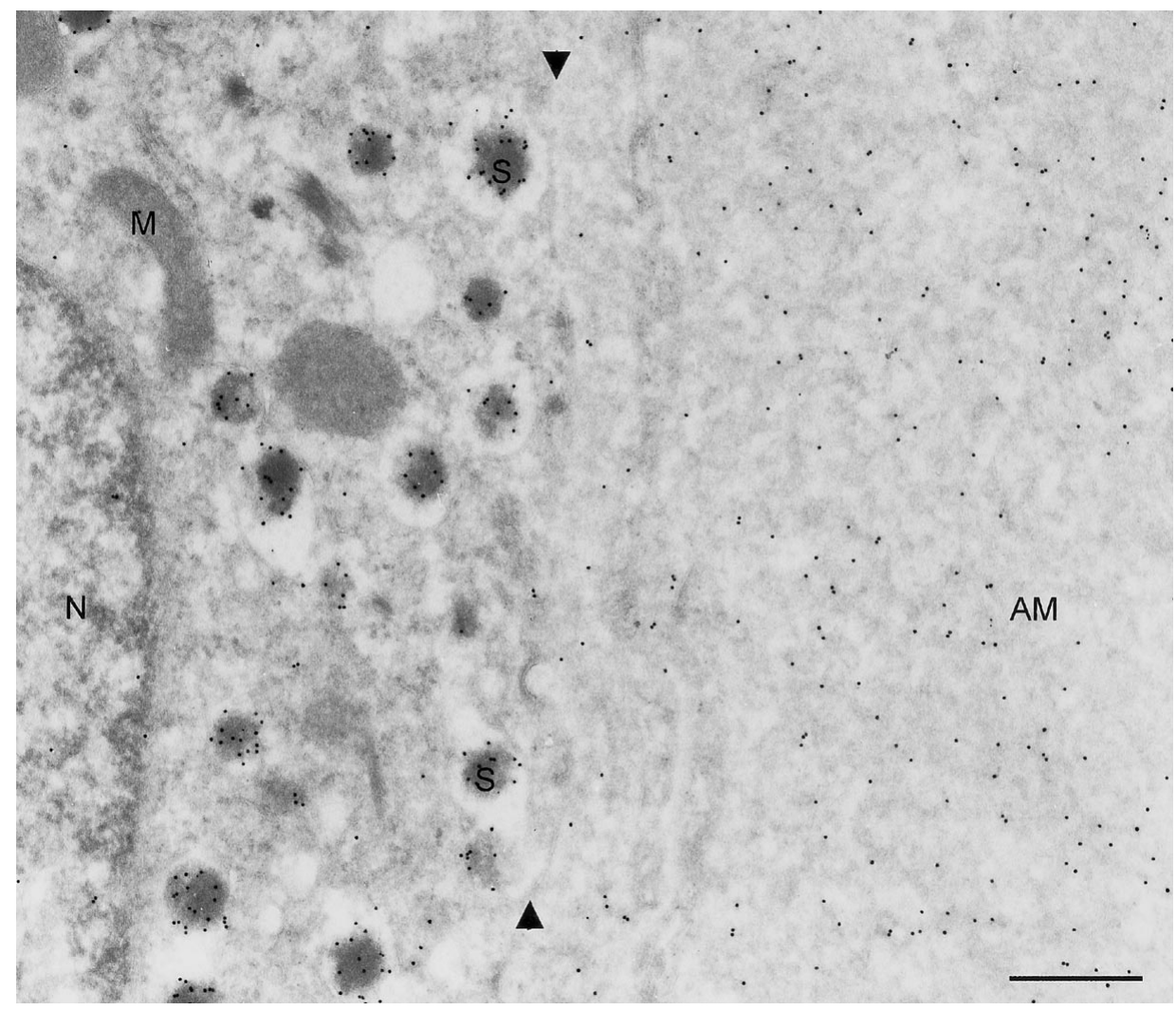

Fig.3. Electron micrograph of a pancreatic islet from a male heterozygous transgenic hIAPP ob/ob mouse (13 months old). Both beta-cell secretory granules (S) and an amyloid deposit (AM) adjacent to this beta cell are immunogold labelled for IAPP. The position of the beta-cell plasmamembrane is indicated by a solid arrowhead at the top $(\boldsymbol{\nabla})$ and at the bottom (A) of the figure. $\mathrm{N}=$ nucleus, $\mathrm{M}=$ mitochondrium. Scale bar is $400 \mathrm{~nm}$, final magnification is $\times 50,000$

Table 2. Number of heterozygous transgenic ( $\mathrm{He})$ and homozygous transgenic (Ho) non-ob/ob $(+/+)$ and ob/ob hlAPP mice of lines No14 and No18, in which islet amyloid was detected in pancreas sections at 16-19 months of age ( $\mathrm{t} 3$ )

\begin{tabular}{lll}
\hline & $+/+$ & ob/ob \\
\hline hlAPP line No14 & $0 / 14 \mathrm{He}$ & $0 / 3 \mathrm{He}$ \\
& $0 / 2 \mathrm{Ho}$ & \\
hlAPP line No18 & $1 / 10 \mathrm{He}$ & $6 / 8 \mathrm{He}$ \\
& $5 / 7 \mathrm{Ho}$ & \\
\hline
\end{tabular}

$25-85 \%$ of the islets, occupying up to $75 \%$ of individual islet areas (Fig. 2) and showing immunogold labelling for IAPP as shown by electron microscopy (Fig.3). The average degree of islet amyloid deposition (Amyloid Index) for amyloid-positive mice was approximately sevenfold higher for hIAPP ob/ob mice than for hIAPP $+/+$ mice $(22.3 \pm 5.6$ vs $3.3 \pm$ $0.8, p=0.005)$.

We also investigated the dependency of islet amyloid formation on the transgenic line (No14 vs No18) and on homozygous compared with heterozygous transgenic state. Islet amyloid was detected only in hIAPP transgenic mice from line No18 (Table 2). Heterozygous hIAPP + / + mice from line No18 generally had two to threefold higher plasma IAPP concentrations than heterozygous hIAPP $+/+$ mice from line No14 (286 $\pm 72[n=13]$ vs $110 \pm 17$ [ $n=14]$ $\mathrm{pmol} / \mathrm{l}$, respectively, $p=0.01)$. Among hIAPP $+/+$ animals islet amyloid mainly developed in homozygous transgenic line No18 mice and rarely in heterozygous transgenic line No18 mice, indicating that high IAPP expression as such can be sufficient for islet amyloid formation. In the hIAPP ob/ob animals, extensive islet amyloid did, however, develop in heterozygous transgenic line No18 mice.

Relations between Amyloid Index and metabolic variables. Human IAPP ob/ob mice with a high Amyloid Index had lower plasma insulin and higher glucose concentrations than those with a low Amyloid Index. This indicated that severe hyperglycaemia in these hIAPP ob/ob mice was related to insulin insufficiency, caused by extensive amyloid formation. Indeed, in hIAPP ob/ob mice with islet amyloid $(n=6)$ the mean plasma insulin concentration at $\mathrm{t} 3$ was fourfold lower than that in non-transgenic ob/ob mice $(n=8)$ $(7255 \pm 3685 \mathrm{pmol} / 1$ vs $31498 \pm 14383 \mathrm{pmol} / \mathrm{l})(p=$ 0.04). In hIAPP ob/ob mice without detectable islet amyloid the mean plasma insulin concentration at $\mathrm{t} 3$ was $37526 \pm 21092 \mathrm{pmol} / \mathrm{l}(n=4)$, which is not different from that in non-transgenic ob/ob mice. Among 

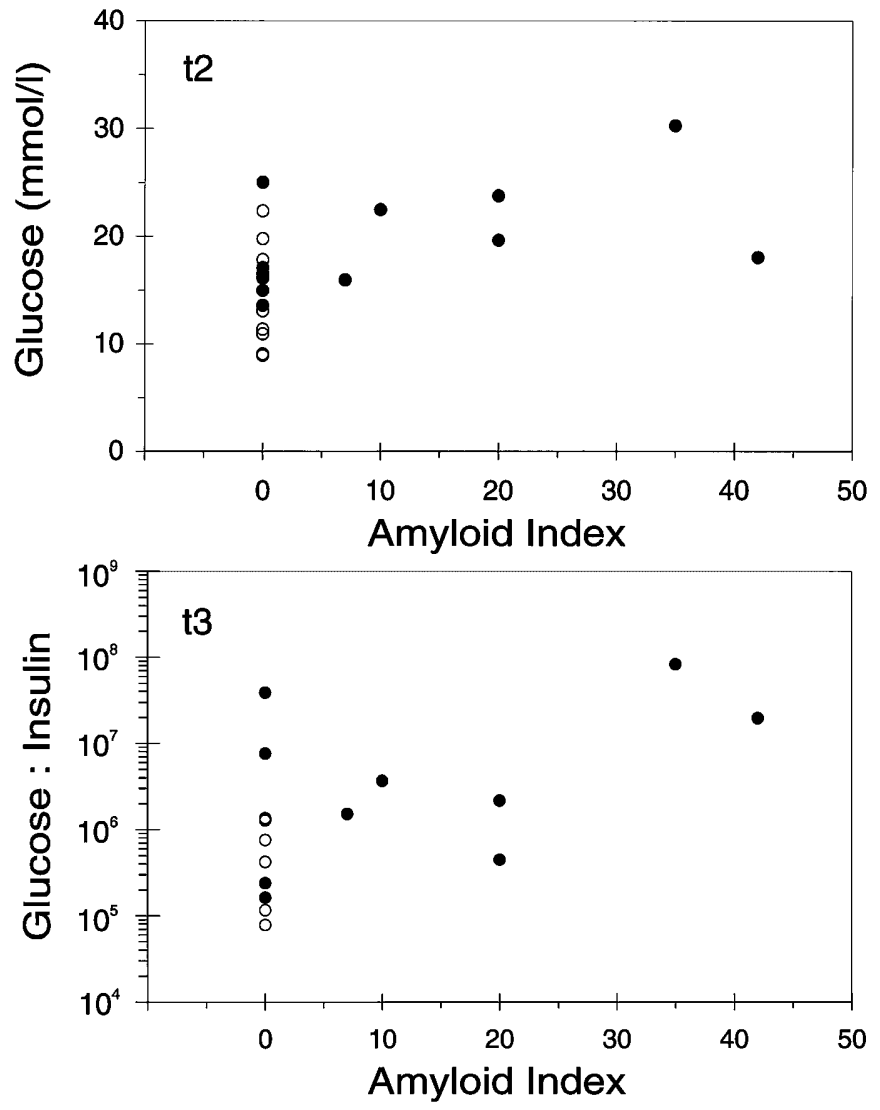

Fig. 4. Correlations between the degree of islet amyloid formation (Amyloid Index) at 16-19 months of age (t3) and the plasma glucose concentration at 6 months of age (t2) (top pan$\mathrm{el}$ ), or the plasma glucose:insulin ratio at $\mathrm{t} 3$ (bottom panel) in ob/ob mice. $\bigcirc$ are data from non-transgenic mice (NT ob/ob, $n=9$ at $\mathrm{t} 2$ and $n=8$ at $\mathrm{t} 3), \mathrm{Ore}$ data from hIAPP transgenic mice (hIAPP ob/ob, $n=11$ at $\mathrm{t} 2$ and $n=10$ at $\mathrm{t} 3$ )

ob/ob mice, the Amyloid Index was positively correlated to the plasma glucose concentrations at $\mathrm{t} 2$ $\left(r_{\mathrm{s}}=0.56, p=0.01\right)$ and to the glucose:insulin ratio at t3 $\left(r_{\mathrm{s}}=0.53, p=0.02\right)$ (Fig. 4$)$. In addition, among the ob/ob mice there was a positive correlation between the Amyloid Index and the plasma IAPP concentrations at $\mathrm{t} 1$ and $\mathrm{t} 2\left(r_{\mathrm{s}}=0.56, p=0.01\right.$, and $r_{\mathrm{s}}=0.59, p=0.01$, respectively $)$.

\section{Discussion}

Non-transgenic rodent models for Type II diabetes lack an amyloidogenic IAPP and many of these models can maintain very high plasma insulin concentrations in the presence of high glucose concentrations. This indicates that insulin resistance rather than insulin insufficiency is the predominant diabetogenic factor in such models. In the majority of patients with Type II diabetes, insulin insufficiency does, however, develop [5] and this may relate to islet amyloid formation $[4,7]$. Thus, to provide the opportunity to mimic islet amyloid-related "exhaustion" or "decompensation" of beta cells, as observed during progression of Type II diabetes in humans, this amyloidogenic factor (hIAPP) might be incorporated in rodent models for this disease.

It is well-known that for mouse models of Type II diabetes, including the ob/ob mice, the genetic background influences the phenotype of the disease. Both our hIAPP transgenic mice and the "ob" strain used for this study were in the $\mathrm{C} 57 \mathrm{Bl} / 6 \mathrm{~J}$ genetic background, which is hardy and able to compensate for insulin resistance [5]. In the non-transgenic ob/ob mice, which develop diabetes in the absence of islet amyloid, the initial hyperglycaemia returns to normal at 18 months of age, due to extensive beta-cell hyperplasia (Figs. 1, 2, [17]). Thus, this made the hIAPP ob/ob $6 \mathrm{~J}$ mice a particularly good model to study the effect of islet amyloid formation on beta-cell exhaustion, i.e. without potentially confounding interference of other beta cell exhausting factors as apparently present in, e.g. db/db mice which show pancreatic islet dysfunction even in non-transgenic animals (unpublished data).

In ob/ob mice of the C57B1/6J background, hyperinsulinaemia arises as early as within a few days after birth and hyperglycaemia is evident even at 6 weeks of age [17]. In this study, both hyperinsulinaemia and hyperglycaemia were indeed evident in NT ob/ob mice at the first point in time investigated, i.e. at 3.5 months of age. Even in homozygous transgenic hIAPP mice of lines No14 and No18, which are normoinsulinaemic and normoglycaemic, no islet amyloid could be detected at 4 months of age [18]. Therefore, insulin resistance in 3.5-month-old heterozygous transgenic hIAPP ob/ob mice most probably developed in the absence of islet amyloid. If islet amyloid was, however, present in heterozygous hIAPP ob/ob mice at 3.5 months of age, it must have been induced by the ob/ob phenotype. Either way, in both cases it leads to the conclusion that extensive islet amyloid formation detected at the age of killing in hIAPP ob/ ob mice was induced as a consequence of the development of insulin resistance/hyperglycaemia.

At 16-19 months of age (t3), concentrations of plasma glucose in hIAPP ob/ob mice were considerably higher than in NTob/ob mice, yet those of plasma insulin were not higher. This suggests an inadequate hyperinsulinaemia in hIAPP ob/ob mice, reflecting insulin insufficiency. Since even at 6 months of age (t2) plasma glucose concentrations were higher in the hIA$\mathrm{PP}$ ob/ob mice than in the NT ob/ob mice and since plasma insulin concentrations tended to be lower (particularly in males, twofold, $p=0.14$ ), it is probable that beta-cell function had been impaired (particularly in males) even at this age. As suggested previously[19], small IAPP aggregates might be cytotoxic, so betacell dysfunction is possibly present before islet amyloid formation can be detected by Congo red staining. 
Insulin resistance and hyperglycaemia not only induced increased insulin production but also increased IAPP production $[14,20,21]$. This co-stimulation is probably due to common transcription regulatory elements in the promoter regions of these two "islet beta-cell specific" genes [22, 23]. Increased hIAPP production promotes amyloid formation. This notion is supported by the findings that 1 ) islet amyloid was detected only in hIAPP transgenic mice from line No18, with higher plasma IAPP concentrations than mice from line No14;2) islet amyloid developed mainly in homozygous transgenic mice [19]; 3) among the $\mathrm{ob} / \mathrm{ob}$ mice, there was a positive correlation between the degree of amyloid deposition (Amyloid Index at t3) and the plasma IAPP concentrations at $\mathrm{t} 1$ and $\mathrm{t} 2$; 4) hIAPP amyloid develops in approximately $50 \%$ of human beta-cell tumours (insulinomas), which overproduce IAPP in addition to insulin [24], i.e. in patients who are hypoglycaemic rather than hyperglycaemic. Amyloid is detected particularly in those insulinomas which have a high IAPP content [25]. Although these data strongly indicate that high hIAPP production rather than hyperglycaemia as such is an amyloidogenic factor, it cannot be excluded that the diabetic state might enhance islet amyloid deposition.

In this study, the hIAPP transgenic model develops only minor amyloidosis in the absence of diabetes, whereas the diabetogenic ob/ob mouse model develops insulin resistance and diabetes in the absence of islet amyloid. The results of crossing these two mouse strains strongly indicate that extensive islet amyloid formation in hIAPP ob/ob mice was induced as a consequence of insulin resistance. On the other hand, both reduced insulin concentrations in ob/ob mice with islet amyloid and positive correlations of the Amyloid Index with plasma glucose concentrations and the plasma glucose:insulin ratio indicate that islet amyloid can also be a cause of insulin insufficiency. These latter results are in accordance with reported in vitro data showing hIAPP amyloid to be cytotoxic to human and rodent beta cells [26]. Amyloid-related loss of beta cells probably also explains why among ob/ob mice plasma IAPP concentrations at $\mathrm{t} 3$ were not higher in hIAPP vs NT animals, whereas this was the case when these mice were younger (Fig. 1 a).

Plasma insulin concentrations in hIAPP ob/ob mice with islet amyloid were lower than in hIAPP $\mathrm{ob} / \mathrm{ob}$ mice without detectable islet amyloid or in non-transgenic ob/ob mice. Our data indicate that islet amyloid is a "secondary diabetogenic factor" which is both induced by and involved in the pathogenesis of Type II diabetes [27]. Thus, a gene encoding an amyloidogenic IAPP molecule constitutes an "endogenous diabetogenic trait" and, like e.g. the "ob" gene, the hIAPP gene can be considered a "diabetogene" [28]. Human IAPP-derived amyloid formation is induced when hIAPP is overproduced, together with insulin, in response to diabetogenic fac- tors which increase the demand for insulin. If the concurrent increase in IAPP production is sufficiently high or persists or both long enough, a "downward spiral" of events is initiated involving amyloid-related loss of beta-cell function, eventually resulting in insulin insufficiency and hyperglycaemia.

Such a role of amyloidogenic IAPP in the pathogenesis of Type II diabetes mellitus is supported by a recent paper describing islet amyloid and diabetes in another hIAPP transgenic mouse model, on another genetic background, crossed with another insulin resistant mouse strain, the agouti viable yellow [29]. We have studied correlations between the degree of islet amyloid formation (Amyloid Index) and plasma IAPP, insulin, and glucose concentrations in individual mice at three different ages. These data enabled us to gain more insight into the longitudinal relations (cause and consequence) between insulin resistance, islet amyloid formation and eventual insulin insufficiency. These analyses showed a predictive value of the plasma IAPP and glucose concentrations for the degree of amyloid formation, since statistically significant positive correlations were shown between the Amyloid Index at t3 (16-19 months) and 1) plasma IAPP concentrations at $\mathrm{t} 1$ (3.5 months), 2) plasma IAPP concentrations at $\mathrm{t} 2$ (6 months), and 3 ) plasma glucose concentrations at $\mathrm{t} 2$.

The hIAPP ob/ob mouse model is well suited for in vivo studies exploring factors and mechanisms involved in islet amyloid formation, as well as its impact on the development of Type II diabetes mellitus. Therapies aimed at interfering with beta-cell exhaustion at an early stage, might preserve endogenous insulin production in subjects developing Type II diabetes. The hIAPP ob/ob mouse model provides an opportunity to assess, in a pre-clinical setting, the effectiveness and possible side effects of anti-amyloidogenic therapies. Such therapies might be targeted towards islet amyloid formation directly or involve reduction of the demand for endogenous insulin (and thus also inhibition of IAPP production), e.g. by the use of pharmaca which improve the sensitivity of target tissues for insulin [30], or by early start of insulin treatment [31] or both.

Acknowledgements. The authors wish to thank L. Kvist (Malmö University Hospital), G. Graad (Dept. Endocrinology, Utrecht), R. Luneborg-Van Netten (Dept. Pathology, Utrecht), E. Dorrestein and T. Hesp (Animal House Utrecht University) for expert technical assistance, Dr. P. Westers (Centre for Biostatistics, Utrecht University) for advice on statistical analyses and W. Verrijp and L. van de Zande (Audiovisual Service, University Hospital Utrecht) for the artwork. This work was supported by grants from the Dutch Diabetes Fund (grant DFN 92.133 to C. O.), Utrecht University Hospital and the Faculty of Medicine, Utrecht University, from the Swedish Medical research Council (grant 14X-6834), Albert Pahlsson and Novo Nordic Foundations, Swedish Diabetes Association, Malmö University Hospital and the Faculty of Medicine, Lund University. 


\section{References}

1. Kahn CR, Vicent D, Doria, A (1996) Genetics of non-insulin-dependent (Type-II) diabetes mellitus. Annu Rev Med 47: 509-531

2. The expert committee on the diagnosis and classification of diabetes mellitus (1997) Report of the expert committee on the diagnosis and classification of diabetes mellitus. Diabetes Care 20: 1183-1195

3. Larsson H, Ahrén B (1996) Failure to adequately adapt reduced insulin sensitivity with increased insulin secretion in women with impaired glucose tolerance. Diabetologia 39: 1099-1107

4. O'Rahilly S (1997) Diabetes in midlife: planting genetic time bombs. Nature Medicine 3: 1080-1081

5. Kahn BB (1998) Type 2 diabetes: when insulin secretion fails to compensate for insulin resistance. Cell 92: 593-596

6. Howard CF (1986) Longitudinal studies on the development of diabetes in individual Macaca nigra. Diabetologia 29: 301-306

7. Clark A, Wells CA, Buley ID et al. (1988) Islet amyloid, increased A cells, reduced B cells and exocrine fibrosis: quantitative changes in the pancreas in type-2 diabetes. Diabetes Res 9: 151-159

8. Röcken C, Linke RP, Saeger W (1992) Immunohistology of islet amyloid polypeptide in diabetes mellitus: semi-quantitative studies in a post-mortem series. Virchows Arch 421: 339-344

9. Westermark P, Wernstedt C, Wilander E, Hayden DW, O'Brien TD, Johnson KH (1987) Amyloid fibrils in human insulinoma and islets of Langerhans of the diabetic cat are derived from a neuropeptide-like protein also present in normal islet cells. Proc Natl Acad Sci USA 84: 3881-3885

10. Cooper GJS, Leighton B, Dimitriadis GD et al. (1988) Amylin found in amyloid deposits in human type 2 diabetes mellitus may be a hormone that regulates glycogen metabolism in skeletal muscle. Proc Natl Acad Sci USA 85: 7763-7766

11. Westermark P, Engström U, Johnson KH, Westermark GT, Betsholtz C (1990) Islet amyloid polypeptide: pinpointing amino acid residues linked to amyloid fibril formation. Proc Natl Acad Sci USA 87: 5036-5040

12. Höppener JWM, Verbeek JS, de koning EJP et al. (1993) Chronic overproduction of islet amyloid polypeptide (IAPP)/amylin in transgenic mice: Lysosomal localization of human IAPP and lack of marked hyperglycemia or hyperinsulinemia. Diabetologia 36: 1258-1265

13. Zhang Y, Proenca R, Maffei M, Barone M, Leopold L, Friedman JM (1995) Positional cloning of the mouse obese gene and its human homologue. Nature 372: 425-432

14. Van Hulst KL, Hackeng WHL, Höppener JWM et al. (1994) An improved method for the determination of islet amyloid polypeptide levels in plasma. Ann Clin Biochem 31: $165-170$

15. Liou W, Geuze HJ, Slot JW (1996) Improving structural integrity of cryosections for immunogold labeling. Histochem Cell Biol 106: 41-58
16. Slot JW, Geuze HJ, Gigengack S, Lienhard GE, James DE (1991) Immuno localisation of the insulin regulatable glucose transporter in brown adipose tissue of the rat. J Cell Biol 113: 123-135

17. Dubuc PU (1996) Transient postweaning expression of excessive fat deposition and diabetes mellitus in ob/ob mice. Growth, Dev Aging 60: 145-151

18. Ahrén B, Oosterwijk C, Lips CJM, Höppener JWM (1998) Transgenic overexpression of human islet amyloid polypeptide inhibits insulin secretion and glucose elimination after gastric glucose gavage in mice. Diabetologia 41: 1374-1380

19. Janson J, Soeller WC, Roche PC et al. (1996) Spontaneous diabetes mellitus in transgenic mice expressing human islet amyloid polypeptide. Proc Natl Acad Sci USA 93: 7283-7288

20. Kahn SE, D'Alessio DA, Schwartz MW et al. (1990) Evidence of cosecretion of islet amyloid polypeptide and insulin by beta cells. Diabetes 39: 634-638

21. Mulder H, Ahrén B, Sundler F (1996) Islet amyloid polypeptide and insulin gene expression are regulated in parallel by glucose in vivo in rats. Am J Physiol 271: E1008-E1014

22. German MS, Moss LG, Wang J, Rutter WJ (1992) The insulin and islet amyloid polypeptide genes contain similar cell-specific promoter elements that bind identical B-cell nuclear complexes. Mol Cell Biol 12: 1777-1788

23. Serup P, Jensen J, Andersen FG et al. (1996) Induction of insulin and islet amyloid polypeptide production in pancreatic islet glucagonoma cells by insulin promoter factor 1 . Proc Natl Acad Sci USA 93: 9015-9020

24. Westermark P, Grimelius L, Polak JM et al. (1977) Amyloid in polypeptide hormone-producing tumours. Lab Invest 37: 212-215

25. Van Hulst KL, Oosterwijk C, Born W, Vroom ThM, Nieuwenhuis MG, Blankenstein MA, Lips CJM, Fischer JA, Höppener JWM (1999) Islet amyloid polypeptide (IAPP)/amylin messenger RNA and protein expression in human insulinomas: Relation to amyloid formation. Eur J Endocrinol 140: 69-78

26. Lorenzo A, Razzaboni B, Weir GC, Yankner BA (1994) Pancreatic islet cell toxicity of amylin associated with type-2 diabetes mellitus. Nature 77: 55-59

27. Oosterwijk C, Höppener JWM, Van Hulst KL, Lips CJM (1995) Pancreatic islet amyloid formation in patients with non-insulin-dependent diabetes mellitus. Implication for therapeutic strategy. Int J Pancreatol 18: 7-14

28. DeMeyts P (1993) The diabetogenes concept of NIDDM. Adv Exp Med Biol 334: 89-100

29. Soeller WC, Janson J, Hart SE et al. (1998) Islet amyloidassociated diabetes in obese $\mathrm{A}^{\mathrm{vy}} / \mathrm{a}$ mice expressing human islet amyloid polypeptide. Diabetes 47: 743-750

30. Zapecka-Dubno B, Czyzyk A, Dworak A, Bak MI (1997) Treatment with metformin in NIDDM patients lowers plasma amylin level. Diabetologia 40:[Suppl.1] A316 (Abstract)

31. Lindström T, Leckström A, Westermark P, Arnqvist HJ (1997) Effect of insulin treatment on circulating islet amyloid polypeptide in patients with NIDDM. Diabet Med 14: 472-476 